Moore, S. \& Stein, W. H. (1951). F. biol. Chem. 192, 663.

National Research Council: Food and Nutrition Board (1950). Repr. nat. Res. Coun., Wash., no. 131.

Robertson, E. I., Carver, J. S. \& Cook, J. W. (1940). Bull. Wash. St. agric. Exp. Sta. no. $3^{88 .}$

Sanger, F. (1945). Biochem. F. 39, 507.

Sanger, F. (1949). Biochem. Y. 45, 563 .

Sanger, F. \& Tuppy, H. (I95I). Biochem. F. 49, 463.

Solomons, C. C. \& Irving, J. T. (1956). Nature, Lond., 178, 548 .

Tarr, H. L. A. (1953). Nature, Lond., I71, 344.

Tarr, H. L. A. (1954). Food Tech. 8, i 5.

Tarr, H. L. A. \& Bissett, H. M. (1954). Progr. Rep. Pacif. Coast Stas Nanaimo \& Vancouver, no. 98, p. 3 .

\title{
Some observations on the biological assay of vitamin $A$ and its precursors by the vaginal-smear method
}

\author{
By PAMELA M. CLARKE AND PAMELA E. E. TODD \\ National Institute for Research in Dairying, Shinfield, near Reading \\ (Received 23 October 1956)
}

The dekeratinizing effect of vitamin A on the vaginal epithelium of the rat was reported by Evans $\&$ Bishop (1922), and various attempts have been made since 1930 to use it as a basis for a biological assay of the vitamin and its precursors. In particular, Pugsley, Wills \& Crandall (r944) have described a method suitable for routine purposes, wherein a quantitative response is given by the number of days needed by depleted rats to become re-depleted after dosing with the vitamin. The method has several attractive features: notably that the response is more specific than in other methods of vitamin A assay, and that the method is economical in that the same animals may be used repeatedly. A further advantage is that the criterion of vitamin A depletion, the characteristic cornified-cell smear, is easily recognized, whereas the corresponding criterion in the assay based on body-weight is poorly defined (see, for example, Bliss \& György, 1951).

In spite of these advantages, however, the vaginal-smear method does not appear to be widely used. Recently we employed it in a series of assays of the biological activity of materials containing isomers of vitamin A: our experience is reported here, to draw attention to the method and to the fact that we found it possible to assume a simpler relationship between dose and response than that used by Pugsley et al. (1944), so that the analysis of the results was also simpler. Some points affecting the design of the assay will also be discussed.

\section{EXPERIMENTAL}

\section{Management of rats}

With only slight adaptations of diets and procedures to those customary in our laboratory, we followed closely the technique of Pugsley et al. (1944). 
Details of feeding and management of our stock colony of black hooded rats are given by Folley, Ikin, Kon \& Watson (1938). Female rats were weaned when 2 I days old on to our diet 213 (Henry, Kon, Mawson, Stanier \& Thompson, I949), consisting of natural materials but very low in carotene and devoid of vitamin $A$, and composed as follows: whole wheat $55^{\cdot 2}$, linseed cake $1 x^{\cdot 2}$, crude casein $4^{\cdot} 8$, dried brewer's yeast $4^{\circ} \mathrm{O}$, calcium carbonate 0.4 , sodium chloride 0.4 , dried skim milk 20.0 and arachis oil (semihardened) $4.0 \%$. The rats were spayed (Ingle \& Griffith, 1949) when they were about 6 weeks old and the vaginas had opened. Two days later they were put on to a synthetic $\operatorname{diet}(\mathbf{1} 72 \mathrm{a}$ ) deficient in vitamin A and composed as follows: ashless extracted casein 15 , dextrinized potato starch 63 , dried brewer's yeast i2, salt mixture (de Loureiro, I931) 5 and arachis oil $5 \%$. The examination of vaginal smears was then begun.

In the ovariectomized rat the vaginal smear normally contains only leucocytes and probably a few epithelial cells. As the rat becomes deficient in vitamin A, cornified cells appear in increasing proportion until in most animals only cornified cells are present, although in some a few leucocytes persist. These different stages in the cellular contents of the vagina have been illustrated by Long \& Evans (I922). Thus, as suggested by Pugsley et al. (I944), a smear showing only cornified cells or cornified cells mixed with a few leucocytes may be taken to indicate depletion. It is important that either of these two types of smear should be regarded as indicative of the depleted state, for if rats giving a smear consisting of cornified cells mixed with a few leucocytes are still further deprived of vitamin A they may become ill and the smears change to the leucocyte stage.

Vaginal smears were made by withdrawing some of the vaginal contents on a blunted dental spatula (blade $1 \frac{1}{8} \times \frac{1}{5}$ in. at base, tapering to a blunted $\frac{1}{10}$ in. bent upwards at an angle of $72^{\circ}$ ), and the adhering material was mixed with a drop of saline on a microscope slide for examination under low power. In this way about twenty smears could be made on one slide. Only one smear was made from each rat at any one time.

With experience, it was possible to use the macroscopic appearance of the withdrawn material to indicate how soon the next smear should be taken. Smears were taken once a week until the material withdrawn on the spatula changed from a rather thin stringy clear mucus to a milky jelly-like substance. They were then taken every and day until cornified cells began to appear, after which smears were made daily so that the ist day of the depleted state, as defined above, was not missed.

As soon as the smear in any one rat indicated depletion the rat was put on to the maintenance diet 213. If the smear then reverted to the leucocyte type, the rat was put back on the synthetic diet until the 'depletion' smear appeared again, whereupon the maintenance diet was again supplied. This procedure was followed with individual animals until there were enough rats showing the 'depletion' smear on the maintenance diet to begin the assay. The reason for this procedure was that the animals succumbed to vitamin A deficiency if they were kept for long on the synthetic diet, whereas they could be kept in good health on the maintenance diet even with a persistent cornified smear. In fact, after the first assay most of the rats continuously gave cornified smears on diet 213 . 


\section{Preparation of solutions}

The Carr-Price test, as described by Thompson (1949) and Fisher, Kon \& Thompson (1956), was used for the chemical estimation of the vitamin A content of the preparations. $\beta$-Carotene was determined spectrophotometrically by the method of Thompson (1949). Values are given in terms of international units, $0.344 \mu \mathrm{g}$ vitamin A acetate being taken as $x$ i.u.

The standard used was crystalline all-trans vitamin A acetate (Roche Products Ltd). A solution in arachis oil containing $0.01 \%$ hydroquinone and $0.1 \% \alpha$-tocopherol was prepared, and the concentration checked by the Carr-Price test. If necessary, the concentration was then adjusted so that the final solution contained the dose in eight $20 \mathrm{mg}$ drops, delivered from a standardized dropping pipette. The highest dose was chosen to give an expected response of less than 30 days, and generally was of the order of I00-I 30 i.u. From this solution, two dilutions in the ratios $2: 3$ and $4: 9$ were made by weighing. The dose levels were slightly increased in successive assays to allow for the tendency, with repeated use of the animals, towards a smaller response to a constant dose of vitamin $A$.

Solutions of the test preparations were similarly made in arachis oil, and their concentrations were adjusted so that the expected biological activities were approximately the same as those of the standard solutions. These concentrations were calculated on the basis of the chemical determinations and on the results of previous biological assays. The preparations used were $\beta$-carotene (crystalline carotene from British Chlorophyll Co. Ltd); a saponified extract of vitamin A from the eyes of Meganyctiphanes norvegica (M. Sars), prepared by the method of Thompson, Ganguly \& Kon (1949); neovitamin A alcohol, prepared as described by Plack (1956); a saponified extract of vitamin A from Thysanoessa raschii (M. Sars), prepared by the method of Thompson et al. (1949). The vitamin A from $M$. norvegica and T. raschii was known to contain large proportions of $c i$ isomers other than neovitamin A (Plack, Fisher, Henry \& Kon, I956).

\section{Administration of preparations}

Rats ready for the test as described above were weighed and transferred to the synthetic diet deficient in vitamin $A$ and were then dosed by mouth morning and evening for 2 successive days with four equal doses of two drops.

\section{Response}

As described by Pugsley et al. (r944), administration of a substance active in vitamin A results in a change of the vaginal smear from the cornified-cell type to one in which leucocytes and epithelial cells predominate. This state is maintained for a period varying with the dose, with eventual reversion to the cornified-cell smear. The response was measured by the number of days that elapsed between the ist day of dosing and the reappearance of a characteristic 'depletion' smear.

Even the lowest dose tested (33.3 i.u.) was found to give a response of at least 6 days. A smear was taken on the 3 rd day after the first dose, and if it still showed a preponderance of cornified cells another smear was taken on the next day. If this smear too 
showed no change, the test material was assumed to be inactive. Any change in the character of the smear after that time must be regarded with suspicion, since our observations confirm those of Pugsley et al. (1944) that it may then reflect illness or infection rather than a vitamin A effect. Generally, however, in the first smear leucocytes or epithelial cells or both together exceeded the number of cornified cells, and subsequent smears were taken on alternate days until the proportion of cornified cells began to increase, whereupon smears were taken daily.

When each rat became depleted it was weighed and returned to the maintenance diet. Any rat that lost more than $10 \mathrm{~g}$ during the test period was deemed unsuitable, and the result obtained with it was disregarded.

When enough rats had been returned to the maintenance diet, another test could be begun. The time taken to complete an assay depends on the doses chosen: with suitable doses an assay can be completed in 5 weeks. 'This period includes $3-5$ days to deplete any rat that has reverted to a leucocyte smear on the maintenance diet and allows for a 4-week experimental period.

\section{Design of the experiments}

The first experiment reported here was carried out to check that the relationship between dose and response for the standard vitamin A was substantially as reported by Pugsley et al. (1944): the experiment involved four logarithmically spaced doses of this preparation. Later experiments were assays of test materials, and were arranged in 6 -point designs, with three doses of the standard and three of the test preparation. A description of an additional experiment to test for after-effects of treatments is given in a later section. In each of these experiments the numbers of rats assigned to the different treatments were equal.

Two batches of rats were used in this series of experiments. The first batch consisted initially of twenty-nine depleted rats, and when this batch was used again for the second experiment, a 6-point assay, it allowed only four rats in each treatment group. Another, and larger, batch of depleted rats was therefore prepared and the first batch was used again only for the experiment on possible carry-over effects, since this experiment involved no more than two treatment groups.

The rats in any one experiment were not all ready for dosing at the same time: in the first experiment the initial doses were spread over about a month, but in all of the remaining five experiments most of the rats were dosed on the same day and the remainder a week later. In the first experiment, which was not statistically planned, the first available rats were allocated mainly to the higher doses; also, the animals were allocated to treatment groups in such a way that the mean initial body-weights of the different groups were approximately equal. In all the later experiments all available rats were equally distributed among the treatments. The second to the fifth experiments inclusive were arranged in randomized blocks on the basis of initial body-weight. This system of distribution did not appear to increase precision and was abandoned in the next assay, in which the rats were simply distributed at random to the treatment groups. In the next, and final, experiment the surviving rats were kept in the same groups as in the previous experiment, and these groups were allocated at random to the 
different treatments. The purpose of this arrangement will be explained later. To summarize, brief descriptions of the experiments in the series are given below:

\begin{tabular}{|c|c|c|c|c|}
\hline $\begin{array}{l}\text { Exp. } \\
\text { no. }\end{array}$ & $\begin{array}{l}\text { Batch } \\
\text { of rats }\end{array}$ & $\begin{array}{l}\text { No. of } \\
\text { rats }\end{array}$ & Purpose of experiment & Design \\
\hline $\mathbf{I}$ & $\mathbf{I}$ & 29 & $\begin{array}{l}\text { Check on dose-response curve; } \\
\text { preliminary ranging test }\end{array}$ & $\begin{array}{l}\text { Treatment groups 'balanced' } \\
\text { for initial body-weight }\end{array}$ \\
\hline 2 & I & 24 & Assay of $\beta$-carotene & $\begin{array}{l}\text { 6-point design; randomized } \\
\text { blocks on bases of initial body- } \\
\text { weight and of order of } \\
\text { depletion }\end{array}$ \\
\hline 3 & I & 16 & $\begin{array}{l}\text { Test of after-effects of treat- } \\
\text { ments }\end{array}$ & $\begin{array}{l}\text { Two groups; randomized blocks } \\
\text { as in Exp. } 2\end{array}$ \\
\hline 4 & 2 & 59 & Assay of $\beta$-carotene & As in Exp. 2 \\
\hline 5 & 2 & 54 & $\begin{array}{l}\text { Assay of vitamin A from eyes of } \\
M . \text { norvegica }\end{array}$ & As in Exp. 2 \\
\hline 6 & 2 & 50 & Assay of neovitamin A & $\begin{array}{l}\text { 6-point design; completely } \\
\text { randomized }\end{array}$ \\
\hline 7 & 2 & 39 & $\begin{array}{l}\text { Assay of vitamin A from eyes of } \\
\text { T. raschii }\end{array}$ & $\begin{array}{l}\text { 6-point design, rats kept in } \\
\text { same treatment groups as in } \\
\text { Exp. } 6\end{array}$ \\
\hline
\end{tabular}

RESULTS

As already stated, the results for those rats that lost more than $10 \mathrm{~g}$ in weight from the time of dosing to the time of re-depletion were discarded, and for the four experiments designed in randomized blocks the resulting unequal numbers of rats in the different treatment groups caused some complication in the analysis. Least-squares methods were used in analysing these experiments, but since neither these analyses nor covariance analysis of the results of other experiments gave any evidence of a significant correlation between initial body-weight and the number of days to re-depletion, the arrangement in blocks was ignored in subsequent work. The difference in date of dosing also appeared to have no consistent effect on the response.

\section{Dose-response relationship}

Pugsley et al. (1944) observed mean responses from $9 \cdot 1$ to 30.5 days for doses of from 50 to 524 i.u., respectively, and found a linear relationship between log days and $\log$ dose over the whole of this range. In the first experiment reported here, which was carried out to test agreement with this finding and to assist in choosing doses in future assays, four doses from 50 to $400 \mathrm{i}$.u. were used. The mean responses were higher than those observed for corresponding doses by Pugsley et al., and the rats that received the highest dose were taking at least 40 days for re-depletion; for practical reasons observations were discontinued beyond this stage. As may be seen from Table $\mathbf{I}$, however, the results for the three lower doses (50, 100 and $200 \mathrm{i}$.u.) agreed well with the assumption of a linear relation between log days and log dose, and the design and preliminary analyses of subsequent assays were therefore based on this premise.

Agreement with this assay model was not, however, maintained throughout the series of experiments. As shown in Table 2, the mean curvature in the two final assays was significant at the $5 \%$ level, a fact that did not appear to be easily explicable by a 
shift with time to a different range of responses. The results suggested that the number of days to re-depletion, rather than the logarithm of this quantity, might give a more useful response metameter, and the experiments were therefore re-examined on this basis. It was then found that in none of the experiments was the deviation from a linear regression on log dose significant $(P<0.05)$.

Table 1. Exp. 1. Mean responses to different doses of vitamin $A$

$\begin{array}{cccccc}\text { Dose } \\ \text { (i.u.) } & \text { No. of rats } & \overbrace{\text { Mean }}^{\text {log days }} & \text { S.E. } & \text { Mean } & \text { S.E. } \\ 50 & 8 & 1.16 & 0.046 & 14.9 & \text { I.32 } \\ 100 & 7 & 1.36 & 0.021 & 23.1 & 1.03 \\ 200 & 7 & 1.55 & 0.015 & 35.4 & \text { I.17 } \\ 400 & 7^{*} & >1.65 & - & >45.2 & -\end{array}$

S.E. $=$ standard error of mean.

* Observations were discontinued after 47 days; the numerical values are therefore derived from results for four rats only.

Table 2. Linear and quadratic components of regression, on log dose, of response to vitamin $A$

$\begin{array}{cc}\begin{array}{c}\text { Exp. } \\ \text { no. }\end{array} & \text { d.f. } \\ \text { I* } & 19 \\ 2 & 18 \\ 3 & 19 \\ 4 & 53 \\ 5 & 48 \\ 6 & 44 \\ 7 & 33\end{array}$

$\begin{array}{cc}\text { Linear } & \text { Quadratic } \\ 0.648 \pm 0.075 & 0.024 \pm 0.124 \\ 0.553 \pm 0.168 & 0.184 \pm 0.291 \\ 0.689 \pm 0.175 & - \\ 0.474 \pm 0.079 & 0.083 \pm 0.139 \\ 0.772 \pm 0.133 & 0.116 \pm 0.231 \\ 0.954 \pm 0.135 & 0.466 \pm 0.226 \\ 1.101 \pm 0.102 & 0.410 \pm 0.192\end{array}$

\begin{tabular}{|c|c|}
\hline \multicolumn{2}{|c|}{ Days } \\
\hline Linear & Quadratic \\
\hline $\begin{array}{l}34 \cdot 0 \pm 2 \cdot 78 \\
20 \cdot 6 \pm 5.93\end{array}$ & $\begin{array}{r}-6.25 \pm 4.62 \\
3.75 \pm 10.27\end{array}$ \\
\hline $27 \cdot 5 \pm 7 \cdot 01$ & - \\
\hline $25 \cdot 5 \pm 3 \cdot 91$ & $I \cdot 55 \pm 6.90$ \\
\hline $24.0 \pm 4.09$ & $0.67 \pm 7.09$ \\
\hline $30 \cdot 3 \pm 4 \cdot 28$ & $11.63 \pm 7.13$ \\
\hline $32 \cdot 0 \pm 3 \cdot 52$ & $4.77 \pm 6.62$ \\
\hline
\end{tabular}

d.f. $=$ degrees of freedom for error variance estimate.

* Omitting highest dose.

Apart from giving better agreement with a straight-line assay model, the use of the untransformed number of days as the response metameter has other advantages. Bliss \& György (I95I) have noted from the results of Pugsley et al. (1944) that taking logarithms had the effect of introducing a wider scatter about the regression line for the lower doses than for the higher doses. Our results confirm this observation. As Bliss ( $195 \mathrm{I}$ ) points out, the correct method of analysis in such circumstances is by fitting a weighted regression line, a much more complicated procedure than the usual one. Both with our results and with those of Pugsley et al.(1944), if the analysis is based simply on days to re-depletion, this difficulty does not arise, since the amount of variation about the regression line is constant over the whole dose range.

\section{Relative potency estimates and precision of the assay}

The potency estimates obtained from the four larger assays are presented in Table 3 to show the precision attained and the comparison with estimates of potency given by other methods. 
Satisfactory precision was attained in all but one assay (Exp. 5), and the wider fiducial limits in this experiment were largely due to a wide difference between the expected activity of the test material and the observed value.

Table 3. Results of a series of four assays for vitamin $A$, carried out consecutively on one batch of rats

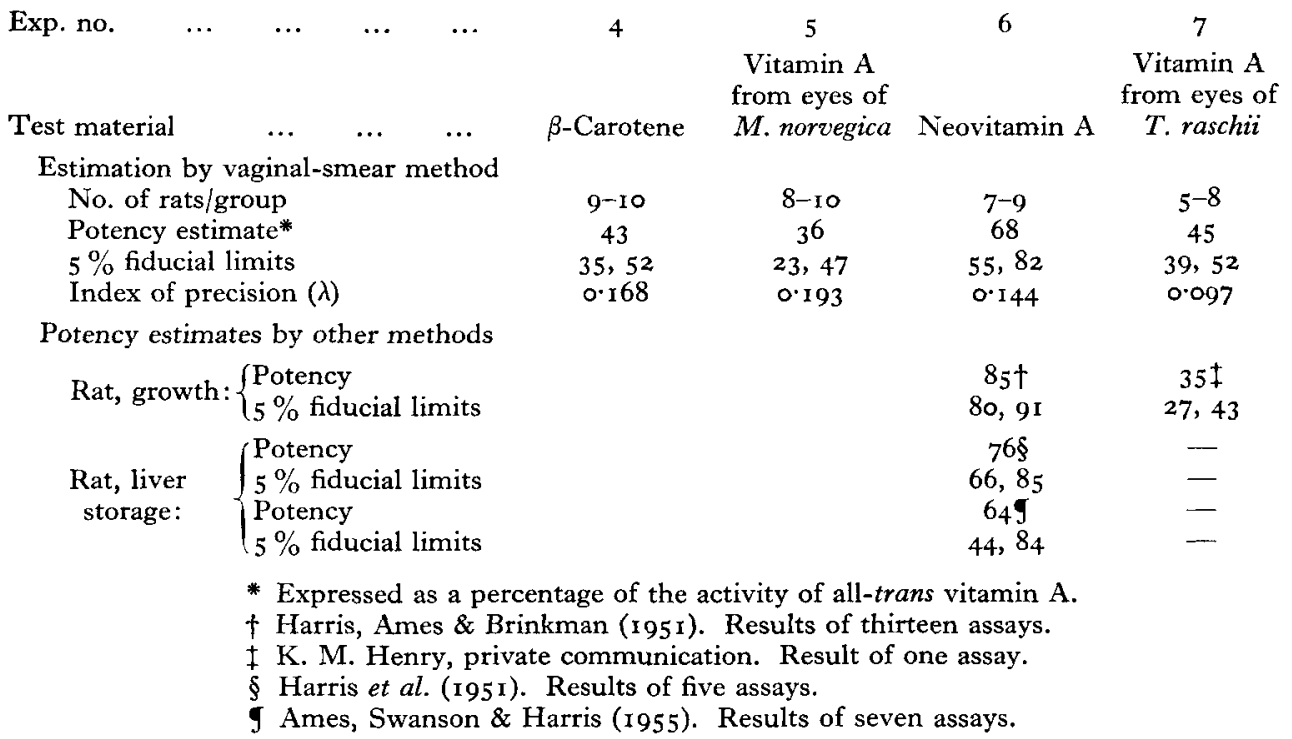

The mean of results obtained in another laboratory for the potency of neovitamin A by the rat-growth method was higher than our estimate by the vaginal-smear method, the difference being significant at the $5 \%$ level. Values obtained by that laboratory in two series of assays by the liver-storage method were, however, in good agreement with our estimate of potency. On the other hand, when the T. raschii preparation was assayed by a co-worker in our laboratory by the rat-growth method, the potency estimate appeared to be lower than that given by the vaginal-smear method, but this difference was not significant $(P>0.05)$.

The index of precision, $\lambda$, which is independent of the numbers of rats and the choice of doses, was calculated for each assay, and these values are also presented in Table 2. The estimates of error variance in the four experiments were combined to give an estimate with 178 degrees of freedom, and a weighted mean of the four coefficients of regression on log dose was calculated. From these, the overall index of precision of the assay was found to be 0.153 . The highest estimate of $\lambda$ in a single assay was 0.193 , which is quite acceptable for general purposes.

On the assumption that $\lambda$ is equal to 0.153 , estimates have been made of the fiducial limits of the relative potency estimate for different experimental arrangements. In an assay of one test preparation against a standard in a 6-point assay, a total of thirty-six rats, six per treatment, would give $5 \%$ fiducial limits of $78 \%$ and $128 \%$ and fortyeight rats, eight per treatment, would give limits of $8 \mathrm{r}$ and $124 \%$, provided the assumed potency of the test preparation were close to the true value. 


\section{Effect of previous treatment differences}

A convenient feature of this assay method is that, once a depleted batch is established, the rats may be used repeatedly. It is then advisable to assess the effect, if any, of differences in previous treatments, and for this purpose an experiment was carried out in which two groups of rats were first dosed with different levels of vitamin A, and in a second period with equal amounts of vitamin $A$. The results are given in Table 4 and show that differences in treatment in the preceding experimental period had no significant effect $(P>0.80)$. This finding was supported by covariance analyses of the results of the other experiments in the series.

Table 4. Effect of the dose in the preceding experiment on the response of rats to vitamin $A$

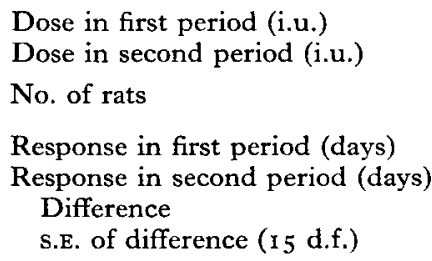

\begin{tabular}{|c|c|}
\hline Group I & Group 2 \\
\hline 55 & IIO \\
\hline 55 & 55 \\
\hline 8 & 8 \\
\hline $12 \cdot 4$ & 18.7 \\
\hline $9 \cdot 5$ & $9 \cdot 7$ \\
\hline & \\
\hline
\end{tabular}

Table 5. Mean response to 60 i.u. vitamin $A$ in successive experiments, estimated from a series of four assays on one batch of rats

\begin{tabular}{clc} 
Exp. & \multicolumn{1}{c}{ Date } & $\begin{array}{c}\text { Mean days } \\
\text { to depletion }\end{array}$ \\
4 & June-July 1955 & $22 \cdot 9$ \\
5 & July--August 1955 & $18 \cdot 6$ \\
6 & October-November 1955 & $13 \cdot 5$ \\
7 & November-December 1955 & $10 \cdot 9$
\end{tabular}

\section{Effect of number of previous treatments}

Results for a series of assays, with the same batch of rats used repeatedly, have shown that, for the same dose of vitamin A, the time to re-depletion decreased with successive assays. This change may be seen from Table 5, which gives the estimated responses (obtained by linear interpolation) to 60 i.u. vitamin A in four successive assays. It should not be difficult to check experimentally whether this result was due to increased age, or to previous experimentation or to season, but at present we have no further information on this question. From Table 2 it may be seen that the decrease with time in mean response was not accompanied by a decrease in slope, but rather the reverse.

\section{Other factors affecting the response}

The results of the whole series of experiments have been examined in detail to discover any factors that might influence the results, so that more suitable designs might lead to increased precision. We have confirmed the finding of Pugsley et al. (1944) that there was no significant correlation of response with body-weight, nor did we find any significant correlation between litter-mates $(P>0.05)$. 
There was, however, a significant correlation between the results for the same rats in successive experiments, after treatment differences had been eliminated. For the first three assays with the second batch of rats, the deviations from the treatment group means showed a correlation coefficient of $0.44(P<0.02)$ between the first and second experiments and a corresponding value of $0.4 \mathrm{I}(P<0.05)$ between the second and third experiments. It appeared, therefore, that adjustment by the results of the preceding assay might reduce the estimated error variance by about $15 \%$. As a further check on this finding, the fourth assay in the series was designed so that the rats were kept in the same groups as in the third experiment, but groups were allocated to treatments at random. This arrangement made allowance for treatment differences more efficient-a useful feature, since the number of rats was by then smaller. Again there was a significant correlation between results in successive experiments $(P<0.02)$.

\section{DISCUSSION}

The main advantages of the vaginal-smear method for the biological assay of vitamin $A$ are specificity, ease of operation, economy of experimental material and high precision relative to other methods described in the literature. The 'depleted' smear was found to be clearly recognizable and different in character from that observed on the preceding day, so that the difficulty in the apparently more widely used rat-growth method of deciding when the rats have reached the appropriate stage of depletion was avoided.

Under our conditions of experiment, a better fit to a straight-line regression on log dose is obtained by plotting the response as the number of days from dosing to redepletion rather than as the logarithm of the number of days, suggested by Pugsley et al. (1944). An important requirement for a good assay method is a mathematical model that adequately fits the observations; it is therefore convenient that, under our experimental conditions at least, the simpler response agrees with a simple and standard model. Not only is it easier to calculate in terms of days, without the labour of taking logarithms, but instability of variance introduced by the use of the logarithmic response is avoided, and the calculations are consequently simpler.

Although none of the experiments reported here involved more than three dose levels within a practicable response range, it is considered that the combined evidence is sufficiently in favour of the arithmetic rather than the logarithmic response. A further experiment to examine the dose-response relation in more detail would, of course, be advantageous, but experimental commitments and resources have so far precluded it. In general, a dose range of 50-120 i.u. was used for assay purposes, and in this connexion it may be noted that the results of Pugsley et al. (1944) show no significant curvature, when the response is measured in days, for doses of from 50 to 128 i.u.

A departure from ideal test conditions in these experiments was that not all the animals in any one experiment were put on test at the same time. The fact that detailed examination of the results disclosed no greater variation for animals dosed at different times than for animals dosed at the same time, nor any clear change in mean response with time within an experiment, does not mean that such an experimental arrangement is recommended. Pugsley et al. found greater variation between occasions than within occasions of dosing, and our results on this point are not sufficient to disprove this 
finding. It is, in any event, obviously safer to begin dosing all the animals in an assay on the same day.

It is perhaps rather remarkable that an assay in which the unit of observation, a day, is so coarse relative to the range of observations, should give such good precision. The overall estimate of the index of precision $(\lambda)$ obtained for four assays in our laboratory was 0.153 , which is satisfactorily low, and in one of these assays $\lambda$ was estimated to be only 0.097. Bliss \& György (I95I), from data reported by Pugsley et al. (1944), calculated even lower values for two experiments $(\lambda=0.063$ and 0.088$)$.

This assay method thus compares favourably for precision with other established methods. Bliss \& György (1951) quote an average index of precision of 0.186 for the 4-week curative growth method with rats, with litter-mate control. In our laboratory, a series of nine assays by the curative growth method, but without eliminating variation between litters, has been carried out over a period of 7 years. The values of the index of precision in these assays have ranged from 0.152 to 0.499 , and in only three of the assays was the value of $\lambda$ below 0.2 (Henry, 1956). The prophylactic growth method and the method based on the cure of xerophthalmia are known to be less precise than the curative growth method. The average value of $\lambda$ for the liver-storage method was calculated by Bliss \& György (195I) to be 0.090 , but the advantage of this low index of precision is offset by the large amounts of vitamin A required. Moreover, the liverstorage method is, strictly speaking, not a measure of the biological activity of a vitamin A preparation in metabolic processes.

The scope for improving the precision of the assay by suitable design is limited, because there are usually some rats that lose more than $\mathrm{log}$ in weight during the experimental period. The results for such rats are discarded, so that the analysis for any arrangement in blocks becomes complicated. This would be less of a difficulty if covariance techniques were used instead of block designs.

So far the only observation likely to prove useful in increasing the precision of the assay in this way has been the correlation between results in successive experiments, when treatment differences have been eliminated. One way of making use of this finding would be to carry out a uniformity trial as soon as the depleted batch of animals is ready and by covariance methods to adjust subsequent results on the basis of these preliminary observations.* Bliss \& György (1951) have suggested that, if successive results are correlated, the assay might be arranged over two experimental periods, effectively using each rat as a block. Our results do in fact show such a correlation, but it is difficult to see how the assay could, as these authors suggest, be completed more quickly by this procedure.

In all the assays reported here the test preparations were in such a form that they could be diluted and administered in the same way as the standard vitamin A acetate. We are satisfied, however, that bulkier materials and materials not soluble in arachis oil can equally well be assayed by this method. We have, for example, carried out tests on whole herring roe offered to rats on small dishes, and on dried materials suspended

* Since this paper was written, an assay has been carried out in this way in collaboration with Dr K. M. Henry. The experimental rats were in poor condition and gave variable results, but application of covariance analysis led to a striking increase in precision, the value of $\lambda$ being reduced from 0.245 to $0 . x 68$. 
in water and administered by stomach tube, and have obtained satisfactory results. We have also successfully used the change in the vaginal smear as an indicator for vitamin $\mathrm{A}$ activity in various whole tissues and fractions of herring gonads.

The use of such test materials raises the question of the effect of oestrogens on the vaginal smear, since the presence of oestrogens in sufficient quantity in the test material might perhaps be expected to reduce the response to vitamin $\mathrm{A}$. Of the natural oestrogens, however, only oestriol appears to be as effective when administered by mouth as when injected subcutaneously, whereas oestradiol and oestrone given by mouth have only I/70 to I/200 times the activity of that given subcutaneously, estimated by the vaginal-smear method on rats (Pederson-Bjergaard, 1939; Fieser \& Fieser, 1949). Until more work has been done on this subject, nevertheless, the vaginalsmear method for assaying vitamin A should perhaps be used with caution for materials that may be rich in oestriol. In this connexion, the results obtained for the test materials derived from herring gonads, referred to above, were confirmed in this laboratory by a modification of the chick liver-storage method (Harrison, I956).

As Pugsley et al. (1944) have pointed out, the response of rats to vitamin A may also be affected by vitamin $\mathrm{E}$. For assays of vitamin $\mathrm{A}$ in foodstuffs containing appreciable quantities of vitamin $\mathrm{E}$, it would therefore be necessary, as they suggest, to add to all doses a constant amount of $\alpha$-tocopherol, sufficient to eliminate any differences due to this factor. In our experiments, however, this problem did not arise, but in accordance with the usual practice in this laboratory, each dose contained about $0.2 \mathrm{mg} \alpha-$ tocopherol.

\section{SUMMARY}

I. The vaginal-smear method of Pugsley, Wills \& Crandall (1944) for the measurement of vitamin A with spayed depleted rats was tested in our laboratory and applied to the assessment of vitamin A potency of several substances.

2. Under our experimental conditions a better fit to a straight-line regression on log dose was obtained by plotting the response as the number of days from dosing to re-depletion rather than as the logarithm of the number of days.

3. The method proved specific and reliable and gave in four assays an index of precision $(\lambda)$ of $0 \cdot 153$.

We are grateful to Dr S. K. Kon and Mr C. P. Cox for interest and advice, to Mr P. A. Plack for the preparation and chemical assays of the test solutions and to Miss M. V. Chapman and Mrs P. A. Plack for technical assistance.

\section{REFERENCES}

Ames, S. R., Swanson, W. J. \& Harris, P. L. (1955). 7. Amer. chem. Soc. 77, 4I34.

Bliss, C. I. (I95I). In Vitamin Methods, Vol. 2, p. 55\%. [P. György, editor.] New York: Academic Press. Bliss, C. I. \& György, P. (I95I). In Vitamin Methods, Vol, 2, p. 4I. [P. György, editor.] New York: Academic Press.

de Loureiro, A. (1931). Arch. Pat., Lisboa, 3, 72.

Evans, H. M. \& Bishop, K. S. (1922). F. metab. Res. I, 35.

Fieser, L. F. \& Fieser, M. (1949). Natural Products Related to Phenanthrene, 3rd ed. New York: Rheinhold Publishing Corporation.

Fisher, L. R., Kon, S. K. \& Thompson, S. Y. (1956). F. Mar, biol. Ass. U.K. 35, 4 I.

Folley, S. J., Ikin, E. W., Kon, S. K. \& Watson, H. M. S. (1938). Biochem. F. 32, 1988. 
Harris, P. L., Ames, S. R. \& Brinkman, J. H. (195 I). F. Amer. chem. Soc. 73, 1252.

Harrison, G. F. (1956). Private communication.

Henry, K. M. (1956). Private communication.

Henry, K. M. \& Thompson, S. Y. (1954). Milchwissenschaft, 9, 14.

Henry, K. M., Kon, S. K., Mawson, E. H., Stanier, J. E. \& Thompson, S. Y. (1949). Brit.F.Nutr.3, 30r .

Ingle, D. J. \& Griffith, J. Q. (1949). In The Rat in Laboratory Investigation, and ed., p. 448. [E. H. Farris and J. Q. Griffith, editors.] London: J. B. Lippincott Company.

Long, J. A. \& Evans, H. McL. (r922). Mem. Univ. Calif. Vol. 6.

Pederson-Bjergaard, K. (1939). Comparative Studies Concerning the Strengths of Estrogenic Substances. Oxford University Press.

Plack, P. A. (1956). Biochem. F. 64, 56.

Plack, P. A., Fisher, L. R., Henry, K. M. \& Kon, S. K. (r956). Biochem. F. 64, I7P.

Pugsley, L. I., Wills, G. \& Crandall, W. A. (1944). F. Nutr. 28, 365.

Thompson, S. Y. (1949). Brit. F. Nutr. 3, 43.

Thompson, S. Y., Ganguly, J. \& Kon, S. K. (1949). Brit. 7. Nutr. 3, 50.

\title{
Factors influencing the rate of excretion of administered chromium sesquioxide by steers
}

\author{
By C. C. BALCH*, J. T. REID and J. W. STROUD \\ Animal Husbandry Department, Cornell University, Ithaca, New York \\ (Received 29 October 1956)
}

Inert markers such as chromium sesquioxide $\left(\mathrm{Cr}_{2} \mathrm{O}_{3}\right)$ are frequently used in digestion experiments to calculate, by means of the ratio technique, the weight of faeces produced; this procedure makes the complete collection of faeces unnecessary. Although earlier the suitability of this method for studies with ruminants was sometimes criticized, it is now widely used with these animals for normal digestibility trials and gives satisfactory results provided the $\mathrm{Cr}_{2} \mathrm{O}_{3}$ is thoroughly mixed with the food (Edin, Kihlén \& Nordfeldt, 1944-5).

In measurements of the intake of grazing animals $\mathrm{Cr}_{2} \mathrm{O}_{3}$ used as a marker provides a means of determining the output of faeces. This is again a considerable saving in labour as it avoids the difficulties of collecting faeces quantitatively from grazing cows or steers. In many experiments in New Zealand and in the United States the number of daily samples of faeces has been limited to two, and the results have shown satisfactory agreement with those obtained by the total collection of faeces. With dairy cows an ideal and common arrangement is for the $\mathrm{Cr}_{2} \mathrm{O}_{3}$ to be given, and rectal samples of faeces to be taken, while the cows are at the milking shed. The use of this procedure might be taken to imply that the content of $\mathrm{Cr}_{2} \mathrm{O}_{3}$ in the faeces remains constant throughout the $24 \mathrm{~h}$. However, investigation has shown that there is a considerable diurnal variation. In grazing cows given $\mathrm{Cr}_{2} \mathrm{O}_{3}$ once daily at about $07 \cdot 3 \circ \mathrm{h}$ there was a low point at $\mathrm{I} 2.00$ and a peak at $\mathrm{I} 8.00 \mathrm{~h}$; the concentration at the low point was 50 , and at the high point $180 \%$, of the mean $\mathrm{Cr}_{2} \mathrm{O}_{3}$ content of the faeces (Hardison \& Reid, 1953). These workers also found that in hand-fed steers, receiving two meals of cut herbage daily at $06.00 \mathrm{~h}$ and $16.00 \mathrm{~h}$, and $\mathrm{Cr}_{2} \mathrm{O}_{3}$ at $07.00 \mathrm{~h}$, there was also a diurnal

* On leave from the National Institute for Research in Dairying, Shinfield, near Reading, England. 